\title{
Metaphor as a window on talk about trauma and post traumatic growth
}

\author{
Adriana Costa* \\ Gerard Steen*
}

\begin{abstract}
People who have suffered traumatic experiences struggle to speak out loud about those events and the resulting pain. At the same time, talking about the trauma and its consequences is a precondition for recovery. This paper adopts Conceptual Metaphor Theory (LAKOFF; JOHNSON, 1980) to investigate how and when trauma sufferers use metaphor as a helpful means to talk and reason about their life stories. It analyzes a set of 7 interviews with traumatized people to study Posttraumatic Growth (PTG), a positive change in people who have struggled with challenging situations in life. The verbal data were analyzed with a cognitive-linguistic approach to metaphor, focusing on a selection of central metaphors for emotions of trauma and life. The patterns that emerged from this analysis were used to construct a model that reveals how survivors use the same conceptual metaphors in two different ways to talk about the different moments of the trauma itself and the subsequent process of recovery.
\end{abstract}

Keywords: Interviews. Metaphor. Posttraumatic growth. Recovery. Trauma.

\section{Introduction}

Although much has been said about the negative aspects of trauma, research has also been conducted to study its potential positive impact. Ordinary responses to very stressful situations tend to persist even after the danger has passed (HERMAN, 1997) and the journey of recovery can be long-but it can also be rewarding. During the healing process victims have the chance to both restore their lives and develop an even more meaningful and rich one. In the past decades, scholars and clinicians have tried to describe what they call Posttraumatic Growth

* Faculty of Arts, VU University Amsterdam, Netherlands. 
(PTG), which has been defined as "the process of developing profound and healthy insights into living as result of surviving trauma" (TEDESCHI; CALHOUN, 1995, p. 29).

Tedeschi and Calhoun (1995) organize aspects of Posttraumatic Growth (PTG) into three categories: changes in philosophy of life, changes in self-perception, and changes in interpersonal relationships. One of the aspects of posttraumatic growth is a deeper appreciation for life. Often this element occurs in combination with the strengthening of one's faith and beliefs. In a posttraumatic growth context, people normally declare themselves to be more connected to people and to have a greater sense of spirituality. As in the recovery process of the trauma, communication is essential to achieve posttraumatic growth. To experience posttraumatic growth it is therefore necessary to realize and understand the situations and attitudes that led up to the victim's current state of being. The trauma, thus, is seen as an essential element in their lives that triggered development and positive change.

Current theories and research of metaphor suggest that emotional, physical and mental disruptions need heavy use of metaphor to think about these experiences, express them in language, and communicate about them with other people (KÖVECSES, 2000; CAMERON, 2011). An analysis of metaphor in therapy and health communication may throw new light on the way people think about trauma and subsequent recovery (TAY, 2013). There are four domains that are prominent in the metaphor literature that seem particularly suitable for such an analysis: the source domains UP/DOWN, CONTAINER, SIGHT, and MOTION.

Metaphorical use of UP/DOWN is one of the most pervasive conceptual mappings that shapes our understanding of life and the world. People seems to conceive good things, health and positive emotions as UP and bad things, illness and negative emotions as DOWN (LAKOFF; JOHNSON, 1980). Therefore it seems obvious that emotional talk makes use of such concepts. Further, in the frame of trauma and the development of Posttraumatic Growth, negative feelings are deeply explored and analyzed in order to gain positive ones (TEDESCHI; CALHOUN, 1995). We therefore expect that UP/DOWN concepts will play a fundamental role in how people talk and make sense of these feelings.

The CONTAINER schema emerges out of our primary embodied experiences. Several unrelated languages and cultures make use of the inside-outside concept in order to understand the relation between body and emotions, in which the emotions happen inside the body (KÖVECSES, 2000). We are therefore interested 
in how the CONTAINER schema is metaphorically applied in people's talk about trauma and recovery.

In making sense of their feelings and life experiences people can establish new goals, reassure or renew their values and plan their life. To look back to our past, to be able to see our current situation and to project our future is a metaphorical process of understanding ourselves in this world. Considering that different cultures exhibit the metaphor UNDERSTANDING IS SEEING, we may expect the use of metaphorical expressions related to the domain of vision in talk about trauma and recovery.

The LIFE IS A JOURNEY metaphor is structured by ideas such as DIFFICULTIES ARE IMPEDIMENTS TO MOTION and PURPOSES ARE DESTINATIONS (LAKOFF; JOHNSON, 1980). The metaphor LIFE IS A JOURNEY sanctions the idea of progress and achievements in life in terms of a physical journey. Further, the journey concept seems to be particularly suitable for events that emphasize stepwise procedures and daily affairs. In this sense, experiencing trauma and PTG also outlines a cluster of interconnected concepts appropriate for conceptualization and development of the metaphor of a journey. The interruption of one's life goals and plans by a trauma, the process of reconstitution of a meaningful world, and the ability to acknowledge the gains of such experience map physical points of this journey. All of these aspects may be reflected in metaphorical uses of MOTION words.

This paper explores the use of the four conceptual metaphors introduced above in the talk produced by trauma survivors who look back on their trauma and recovery. We analyzed a set of 7 interviews with traumatized people who experienced Posttraumatic Growth - PTG -. The verbal data were analyzed with a cognitive-linguistic approach to metaphor identification and analysis, focusing on the above selection of central metaphors for emotions of trauma and life. Our goal is to examine the way these are used and reflect on their relationships in such a way that a model may be constructed for further research.

\section{Method}

The interviews analyzed in this paper were initially collected for a doctoral research project at Adelphi University-Demer Institute of Advanced Psychological 
in Long Island, NY, and were provided for this study by Dr Kate Szymanski, committee chairperson of the research, with the permission of the Institutional Review Board (IRB). The aim of the doctoral research was to investigate the process of meaning making and posttraumatic growth. The structure of the interviews was, therefore, shaped in order to understand how the processes of recovery and healing are perceived, how individuals make sense of what has happened to them, and how they changed as a result of the experience. Since many interviewees had not been in therapy, they are not patients. The interviews were semi-structured and of a research kind-they cannot be seen as therapeutic talk either. The total number of words was 76,519, averaging 10,931 per interview.

Based on the illustrations in the cognitive-linguistic literature and the most relevant and frequents words identified in the first two interviews, a limited inventory of 22 interesting target words was made:

\begin{tabular}{|c|c|}
\hline UP/DOWN & High, lift, up, down, deep, bottom \\
\hline CONTAINER & Out, into, open, inside, stuff \\
\hline SIGHT & Outlook, see, look, clear \\
\hline MOTION & Move on, go on, path, way, forward, leave, through \\
\hline
\end{tabular}

The rest of the data was then analyzed to check whether these words were really relevant to the trauma and recovery scenario and when and how exactly they were used. Every single word of the list and their different forms were tracked within the protocols and analyzed according to the contexts in which they were found. In total, 816 instances of the 22 target words emerged from the data.

\section{Results}

\section{UP/DOWN}

The main picture created by the metaphorical use of words related to the UP/ DOWN grouping refers to how traumatized people talk about their issues, their feelings and themselves. 
(01) And I had a different apartment in this building 2 years before I hit bottom.

(02) At the time, deep shame, deep shame.

The positive feelings or moments of progress during the healing process are expressed with words connected to the idea of UP. The words high and lift from the UP/DOWN grouping are particularly relevant in these interviewees' narratives, which describe the transformation of bad emotions and states into positive ones. Analysis of the data reveals that the word lift is normally used to describe milestones of relief in the interviewees' journey. They mark a particular event associated with progress in the healing process.

(03) I felt like $500 \mathrm{lbs}$. had been lifted off me because I really felt for the first time that I had an illness and I was not bad.

The word high is also metaphorically used by the interviewees to talk about moments of recovery in their narratives. What is striking is that this word is often used in a spiritual and religious connotation. Conceiving something spiritual or celestial as something high or existing in a higher place is part of a western Judeo-Christian culture that perceives heaven as a place higher than the earth. The example below is part of an victim's narrative about the moment in her life that she felt like she was being chosen and guided towards a greater purpose in life:

(04) ... even at the time this felt much bigger than me. It felt like this was coming from a much higher place and I was being moved from here to someplace I didn't know where.

In accordance with this idea, the adjective higher, as in higher place, imbues the object with divine and superior qualities. An example of how this appears in the data is given below:

(05) But it's being able to share it from somebody else and come from like a higher place in myself that was somehow above the trauma.

A second main idea is now illustrated. Metaphorical uses of words from the UP/DOWN grouping here indicate the notion of particular directions that people can take in life:

(06) I could either die, not physically but spiritually and I could just sink and give up or I could go down the other road of growth and healing and you know developing and so forth.

These sentences presuppose the idea of a path, or road, being traveled and the possibilities of different directions that can be followed by the traveler. The 
schema of a path is reinforced by the use of the word up in a similar case. However, in this case, the word up indicates not only the concept of a path but also the understanding of this path as a continuum in time.

(07) I knew that who I was going to be from then on was totally different from who I had been up until then.

There are therefore two analyses involved in this part of the UP/DOWN grouping. The first analysis is the understanding of this path as a continuum in time that situates past (path already traveled), present (path being traveled) and future (path to be traveled). The second is the conception of different directions to be taken in life, and therefore a path being followed. Their combination is coherent with the scenario of the LIFE IS A JOURNEY metaphor. In this scenario the individual is a traveler, his or her purposes in life are destinations, locations along the way are moments in life and progress is the distance traveled. We will explore this idea further below.

\section{CONTAINER}

The words from the CONTAINER grouping are mainly connected to how interviewees express the dynamics of their feelings in the trauma and recovery context. Interviewees acknowledge that they stuffed their feelings related to the traumatic experience. They also understand the need to look into themselves and to get in contact with the emotions that they kept inside and bring them out. Further, they conceive the idea of opening themselves up as a precondition to healing.

The word into, however, seems to be deployed in an even broader sense of the meaning than the one described above. Interviewees not only use this word to express the idea of containment of themselves but also to talk about certain situations:

(08) that just represented the end of anything that I had any connection with respectability, and I went into another depression.

(09) So then when I got into recovery there was all this shame of having done that.

Yet, the rest of the words belonging to the CONTAINER group are mostly used by interviewees to refer to themselves. The word inside, for example, plays an important role in how interviewees understand the relationship with their feelings. They seem to acknowledge that whatever they keep inside needs to be accessed 
in order to heal. In the trauma context, to get to know your self means to be able to probe into your own feelings, thoughts and values as an essential part of the recovery. In fact, evidence from the data shows that interviewees understand the search for healing as something that originates within themselves:

(10) And I'm smart enough to know that things, external things don't do that. That comes from inside.

(11) I've always been a searcher. I think I searched outside and then I started searching inside and if there was meaning it was, to maybe tenderize my pride.

If interviewees assume that inside is where their feelings occur and where the transformation begins, they also acknowledge the need to express those feelings, memories and emotions regarding the trauma that they have suppressed. Further analysis of the UP/DOWN grouping suggested that interviewees understand the inability to talk about or even to admit to the existence of these feeling as an attempt to hide them inside. Considering that talking about and exploring the feelings related to the traumatic memory is a precondition for healing, the interviewees seem to understand the act of hiding feelings inside themselves as something negative. The idea that these feelings need to come out is reinforced by the appearance of the word out in this same context along the data.

(12) I guess I got it all out of my system.

(13) And what made it go away was just kind of talking about all the things that I'm anxious about and putting them out there.

The word out is also used to express the process of getting in contact and reestablishing connections with the world. Trauma can result in significant isolation and withdrawal of the victim. The ability to open themselves up is crucial for the interviewees' recovery since talking about the traumatic experience is a requirement to rebuild the interviewees' reality (HERMAN, 1997). Therefore, the use of metaphorical expressions related to this domain helps to express the idea of leaving this isolated inner place to again be connected with people in an outer life.

(14) I think you have to reach out and ask for help.

(15) And that got me to the point where I surrendered and I entered the now and self was allowed to come out and show me what it was all about.

This idea is complemented by the constant presence of the word open in the data in a context of reestablishing connections with the outside world. Interviewees often use this word to talk about their new attitude towards people and life, as illustrated below. 
(16) And it began to open me up because I was so shut down emotionally all the time.

(17) That there is healing and there is transformation and you'll find your path, you'll be led if you're open to it.

\section{SIGHT}

Words related to sight are basically used to express the survivor's ability, or difficulty, to reflect on the trauma and their stories. In fact, the process of making sense of the survivors' journey through trauma and recovery still happens even during the interviews that comprise this data:

(18) Looking back I probably felt less than other people, part of that was that I didn't have anything.

The need and importance to face the trauma and its consequences is also expressed by the interviewees' narratives. The words from the SIGHT grouping are used to refer to moments in which the interviewees look at their trauma, see how it works in their lives and gain a clear understanding of their situation. The examples below exemplify these moments:

(19) When you know what it is and you're dealing with it, it's not as traumatic because you look at it and you say, Okay, that's what that is. I need to do something about it.

(20) When I first went to 12 Step programs I was terrified because I saw all this intimacy and on the surface I could fake it and participate but as I started to get more honest with myself I realized I was faking it and that nobody really knew who I was.

(21) Because I, some place along the way I saw, it became very clear that I had, could go down one of 2 roads.

To be able to look back at their previous life, values and attitudes and analyze their choices and current situation is also fundamental for victims to overcome the trauma. Moreover, a pre-condition for Posttraumatic Growth is the survivor's ability to reflect on the aspects of the traumatic event in order to reconstruct a meaningful world (CALHOUN; TEDESCHI, 2006). In this scenario, interviewees frequently use the word 'look' to refer to their process of making sense of their life stories.

(22) When I look back on it, the way I discovered to get away from my family 
was to going for education because none of them are educated so it could not be a shared experience.

(23) I was incapable of breaking up the relationship. But I would create an environment, this is looking back, I always created an environment where they would.

In contrast with the picture above, the narratives about the trauma, or the period around it, suggest a great difficulty in seeing things. In fact, according to Wertheimer (2011), one of the main effects of the trauma is the struggle to understand what has happened. The words from the SIGHT grouping identified in this section of the narratives consequently emerge in the context of momentary lack of sight.

(24) Well, near the end, like, just kind of surviving. Going to my job, not seeing much in the future and being a wild lady on the weekend. And really not caring.

(25) I think it had a very powerful impact but in ways that really took me a long time to see.

\section{MOTION}

The words in this grouping clearly identify the concept of a path or a road being travelled. An obvious example is the expression through use of the words path and way. The examples below illustrate how interviewees understand and refer to their life stories as a pathway.

(26) Um, I just go on a different path, a different journey.

(27) So there were a lot of people that helped me out along the way, but I didn't get close to anybody.

Metaphorical use of the MOTION word through in these interviews also fits the journey perspective. It is used to refer to situations encountered by the survivors, which means a particular point of the journey that the people went through. Moreover, this word is also used by individuals to explain ways by which they handle certain situations, reach different points in their journeys and achieve particular goals in their lives. Example (28) illustrates cases in which through is related to a situation, (29) indicates how through refers to the ways in which interviewees handle those situations:

(28) But I had a purpose, a reason for going through everything I did and that 
there was a reason.

(29) And once people get that then it opens up the door that they can do through behavioral changes and cognitive work and all the emotional work, they can develop new ways of dealing with their trauma.

When the individuals talk about the traumatic event and the short period thereafter, words from the MOTION grouping are mainly used to refer to other people, lives or time. This suggests that the speakers see themselves in a static position. The feeling of being stuck or paralyzed is explained by the fact that trauma, and the crisis that follows, breaks the regular flow of life (TEDESCHI; CALHOUN, 2004).

(30) I just couldn't accomplish, I didn't know what was going on and I wanted to really run away.

(31) Leave them alone, they've moved on with their life.

(32) I was just completely losing myself. I said that a number of times but it was, the drinking was taking me and I couldn't stop. And it was difficult, you know, like one more peel of the onion and there was nothing left.

However, this pattern changes and is left behind as soon as interviewees start to heal and move on with their lives. The first example in the list below is the statement of someone who lost her whole family in a car accident when she was a child. The second narrates the moment in the interviewee's life in which she realized that she did not have any other choice at the time but to send her son for adoption and therefore ease up her guilt. The last one refers to the speaker's confrontation with his abusive stepfather:

(33) But after a while, you know, the shock kind of wears off and you realize that you have to go forward. And the best way to go forward is to not harp on the past but to try and you know live each day again.

(34) So then I went on and I had Adam in my life and later we got married and we traveled around the world but I really, cried for about 7 years about losing this child.

(35) Now I was pretty much done, I knew I was never gonna, we were never gonna be buddies but it was something that I had to do to move on.

To be back in metaphorical motion is also a condition for Posttraumatic Growth since PTG is intertwined with the natural progress of the life narrative. As mentioned by the survivors, the healing and the personal development is an ongoing process and not the final result of their struggle (CALHOUN; TEDESCHI, 2006). 
(36) Okay. And I think the healing to some extent is still going on. The whole trauma, I mean it was not a trauma, it was this 20 -year trauma.

(37) So I know there's a lot of healing going on.

One final observation must be made here. Although survivors are referring to something other than themselves, the motion in these statements is happening now. Survivors are now integrated in the natural motion of life.

\section{Discussion}

The analysis developed in this paper has suggested a recurring pattern in the use of particular metaphorical expressions in narratives about trauma and recovery. We will now propose a simple model in which metaphorical expressions can be organized according to the dynamics of the trauma and the healing process. The model proposed therefore comprises two different scenarios (trauma and healing) that derive from the same basis: how and when the main recurring word groups in the data occur depends on the moment in the trauma or healing process that the individual is discussing. An explanation of the shared basis and how the scenarios work will follow below.

The basis - The basis of all four groupings can be structured by one common element: the understanding of life as a path or road to be travelled. Survivors express the conceptualization of their trauma experience as if it is a physical path using different words from the four groupings (UP/DOWN, CONTAINER, SIGHT, and MOTION). From this perspective, traumatized people refer to different moments of their lives as physical points on their journey. They transport themselves into particular places and travel along this path to make their way through many situations. People can follow different directions and go down different roads. During this travel they are able to look back, to events behind them, and forward, to possibilities in their future.

Scenario I - This scenario draws on how victims express themselves about the direct aftermath of the trauma. The metaphorical speech deployed here by the survivors creates a scenario of:

No MOTION

DOWN 


\section{Closed CONTAINER}

No SIGHT / Blindness

Traumatized people seem to observe themselves in no motion during the trauma or in its aftermath. This idea is mainly supported by the use of different words related to motion that refer to other people, time and life but not about themselves. From this perspective, people move on, time goes by, life goes on. The victims themselves, however, remain still. Consistent with this idea is the fact that narratives from this period of their life include specific words related to their own motionless state. The feeling of being stuck or paralyzed is coherent with the Tedeschi and Calhoun (2004) explanation that the trauma and the following crisis interrupt the regular course of life. Before the trauma people would go through life, going to school, following a career path, going on dates, going out with friends, etc. Accounts like these become nearly nonexistent in narratives of the traumatic period. In the first scenario, therefore, such metaphors generate the notion of No MOTION.

Metaphoric systematicity derived from the concept of DOWN is also part of this scenario. People exhibiting PTG use words and expressions related to this grouping in two different ways. The first refers to their negative feelings and states. Depression, despair and sorrow dominate feelings in the trauma context and are often addressed through expressions such as feeling down or hitting the bottom. The second is related to the intensity of feelings. Since trauma and its aftermath are such overwhelming experiences, metaphorical speech suggesting that these feelings take place in deeper levels of the individual may include words and expressions such as profound and deep down.

The concept of a CLOSED CONTAINER is generated by a common effect of the trauma in which survivors are led to withdrawal and isolate themselves. The idea of isolation is expressed using the image of a closed container, where emotions are kept inside. Although contained, these emotions are not necessarily negative. As shown by the analysis, the decision to change and to heal also comes from inside. However, it is necessary that these feeling come out and become materialized in the outside world. Although the will to heal comes from inside, the transformation only begins to take place when the trauma is shared (HERMAN, 1997). Shut in and bottled up are more obvious examples of the CLOSED CONTAINER feature.

Interestingly, words related to sight are not frequently observed in this 
scenario. The nature of trauma demands time and great effort from victims in order to process what has happened and start to make sense of everything. Therefore, since reasoning is metaphorically understood as seeing, very few metaphors in this moment of the narrative are related to the SIGHT grouping. In fact, this moment is marked by the confusion and a lack of understanding of the situation. Moreover, any metaphorical speech related to SIGHT deployed in this scenario normally express a difficulty to see. Thus, the notion of SIGHT loss or even blindness is another feature in scenario I.

Scenario II - The second scenario refers to later stages of the therapy and eventually to PTG. It therefore provides a representation of the victims' understanding of the trauma, the healing process and their current self and situation. Again, the same four word groupings are presented, this time, however, with opposite characteristics to scenario I:

\section{More MOTION \\ UP \\ Opened CONTAINER \\ Enhanced SIGHT}

During the healing process survivors find new tools and ways which can help them to move through this experience. Slowly, victims begin to get released from their static position and are able to move on with their lives. The return to life activities and the establishment and accomplishment of new goals reinforce the idea of more MOTION in the second scenario. Moreover, the acknowledgment that the healing process is ongoing also contributes to the use of metaphorical words related to the MOTION grouping.

People's narratives about their healing are pervaded with words related to UP. They often report the feeling of being lifted from this bad place or situation provoked by the trauma. Further, Posttraumatic Growth is also characterized by the development of a greater spirituality, which is often reported by trauma victims as something that comes from or is connected to a higher place or force. The appearance of the word high in narratives of spiritual rising shows the religious context in which this word is used. Narratives of the recovery process also include sections in which survivors refer to their ability to bring up their feelings and emotions. This idea is coherent with the previous scenario, in which interviewees 
describe their feelings regarding the trauma as settled deep inside them. In fact, the process to bring up the trauma issues is an essential part of the recovery (HERMAN, 1997).

In the very same way, traumatized people need to release the negative feelings and thoughts related to the trauma that they keep inside them. They must open themselves to life and to the world again. During the period of the trauma and its aftermath people withdraw and shut into themselves, but during the healing process they start to open themselves up. They then learn how to reconnect with people and reality and how to recover old relationships while establishing new ones (HERMAN, 1997). Thus, the image of an open CONTAINER is strongly present in scenario II.

If scenario I suggests possible blindness, scenario II is strongly defined by the victim's ability to reflect about the trauma and their stories. To look back and reflect on their previous life, values and attitudes and analyze their choices and current situation is fundamental in overcoming the trauma. Even more, the ability to reflect about the different elements that compose a traumatic experience is essential to restore a meaningful world (CALHOUN; TEDESCHI, 2006). In this scenario interviewees not only express themselves as being able to look back, but also to see things clearer. Thus, this scenario is strongly characterized by enhanced SIGHT.

Both scenarios are connected by the same dimensions of the trauma. The overwhelming experience of the trauma affects the bounds between the victim and the others. Trauma can cause survivors to isolate themselves and break their relationships with family and friends. During recovery, victims learn how to open up themselves again and reestablish connections with the outside world. This process is achieved through communication with others. People need to bring up and share the feelings that they have kept deep down inside them. Verbalizing their experiences victims are able to reason about the trauma and see things that they were unable to realize during the traumatic period. Once they have done that, they can set their lives, which have been interrupted by the trauma, in motion again. Reaching the next stage of this process is defined as a positive outcome of the whole situation. In this new context, people become more open to people and are able to see events in the past even clearer and look further in the future. 


\section{Conclusion}

Research suggests that the LIFE IS A JOURNEY metaphor is ultimately based in a source-path-goal schema. From this perspective, scenario I can be considered to be the SOURCE of the survivor's journey. It is the point from which they begin their journey through recovery and reconstruction of their life. Scenario II portrays both the PATH and the GOAL of the journey. This is due to two main reasons. First, healing is an ongoing process. The trauma is never forgotten, which means that trauma victims are still walking this path. Second, interviewees in this study have all experienced Posttraumatic growth, which gives them a greater ability to analyze their stories. Therefore this scenario represents not only the actions and improvements themselves but also people's perceptions of them. The understanding of their search for help, their healing process and their positive gain from the situation are, therefore, presented in scenario II.

The two scenarios and their four metaphorical dimensions comprise two sides of the same medal, the original trauma and the subsequent move away from it in recovery. The way in which this is signaled by metaphorical word use may be an important tool for health workers and patients to get a grip on their abilities to understand and communicate. For linguists, they present an opportunity to build a bridge between fundamental and applied research on the relation between metaphor in language, cognition, and communication. 


\title{
Metáfora como uma janela para a discussão sobre trauma e crescimento pós-traumático
}

\begin{abstract}
Resumo
Vítimas de eventos traumáticos enfrentam dificuldades para falar sobre as dores e horrores vividos. Entretanto, falar sobre o trauma e suas consequências é essencial para o processo de recuperação. Este trabalho adota a Teoria da Metáfora Conceitual para investigar como e quando pessoas que vivenciaram um trauma utilizam metáforas para falar e refletir sobre suas histórias de vida. Neste artigo, analisamos um conjunto de entrevistas realizadas com pessoas que experienciaram Crescimento Pós-Traumático, ou seja, mudanças psicológicas positivas após o confronto com situações de vida extremamente adversas. Os dados foram analisados sob a perspectiva da linguística cognitiva de identificação e análise de metáforas, com foco em uma seleção de metáforas centrais para emoções ligadas ao trauma e a vida. Os padrões evidenciados por esta análise foram utilizados na construção de um modelo que evidencia como sobreviventes utilizam as mesmas metáforas conceituais de maneiras distintas, de acordo com o momento de vida narrado.
\end{abstract}

Palavras-chave: Metáforas. Trauma. Crescimento pós-traumático. Recuperação.

References

CALHOUN, Lawrence; TEDESCHI, Richard. Handbook of posttraumatic growth: Research and practice. Mahwah: Lawrence Erlbaum Associates, 2006.

CAMERON, Lynne. Metaphor and reconciliation: The discourse dynamics of empathy in post-conflict conversations. New York: Routledge, 2011.

HERMANN, Judith. Trauma and recovery: The aftermath of violence: from domestic abuse to political terror. New York: Basic Books, 1997.

KÖVECSES. Zoltán. Metaphor and emotion: Language, Culture, and Body in Human Feeling. Cambridge: Cambridge University Press, 2000.

LAKOFF. George; JOHNSON. Mark. Metaphors we live by. Chicago: University of Chicago Press, 1980. 
PSALM 103:11. In Holy Bible: New International Version: standard rainbow study Bible, every verse color-coded. Cincinnati: Standard Pub, 2012.

TAY, Dennis. Metaphor and psychotherapy: A Descriptive and Prescriptive Analysis. Amsterdam/Philadelphia: John Benjamins, 2013.

TEDESCHI, Richard; CALHOUN, Lawrence. Helping bereaved parents: A clinician's guide. New York: Brunner-Routledge, 2004.

TEDESCHI, Richard; CALHOUN, Lawrence. Trauma and transformation: Growing in the aftermath of suffering. Thousand Oaks: Sage, 1995.

WERTHEIMER, Alison. A special scar: The experiences of people bereaved by suicide. London: Tavistock/Routledge, 1991. 

Entrevistas 
